\title{
INTERVENSI KEMANUSIAAN (HUMANITARIAN INTERVENTION) MENURUT HUKUM INTERNASIONAL DAN IMPLEMENTASINYA DALAM KONFLIK BERSENJATA
}

\author{
Emi Eliza \\ Fakultas Hukum Universitas Lampung \\ Email : emieliza92@gmail.com \\ Heryandi \\ Fakultas Hukum Universitas Lampung \\ Ahmad Syofyan \\ Fakultas Hukum Universitas Lampung
}

\begin{abstract}
Humanitarian intervention is an attempt to prevent or stop the gross human rights violations with particular strengths (diplomatic and military) in a State, either with or without the consent of the State (countries with internal conflict). The problems in this journal are: first, how the arrangement of international law on humanitarian intervention. Secondly, the role of the UN in humanitarian intervention in armed conflicts. The method used is a normative legal research methods with the main source of data collection procedures is a legal substance that contains of normative law. The results showed that the rules of international law on humanitarian intervention by the United Nations stipulated in the UN Charter and general principles of international law. Humanitarian intervention legally justified by following provisions in applicable international law, namely Articles 39-51 of UN Charter. While the role of the UN in humanitarian intervention in armed conflicts carried out by the Security Council as the organ of the United Nations in maintaining peace with the decision issued in the form of a resolution for areas experiencing conflict. Therefore, it takes an international treaty that regulates clearly about humanitarian intervention, so that in practice, remain consistent with the objectives and executive organs of humanitarian intervention.
\end{abstract}

Keywords: Humanitarian Intervention, Security Council of UN, Armed Conflict.

Intervensi kemanusiaan merupakan upaya untuk mencegah atau menghentikan pelanggaran HAM berat dengan kekuatan tertentu (diplomatic and military) di suatu negara, baik dengan atau tanpa persetujuan dari negara 
(countries with internal conflict). Masalah dalam jurnal ini adalah: pertama, bagaimana pengaturan hukum internasional tentang intervensi kemanusiaan. Kedua, bagaimana peran PBB dalam intervensi kemanusiaan dalam konflik bersenjata. Metode penelitian yang digunakan adalah metode penelitian hukum normatif dengan sumber utama prosedur pengumpulan data adalah bahan hukum yang berisi aturan-aturan hukum normatif. Hasil penelitian menunjukkan bahwa peraturan hukum internasional tentang intervensi kemanusiaan yang dilakukan oleh PBB diatur dalam Piagam PBB dan prinsip-prinsip umum hukum internasional. Intervensi kemanusiaan secara hukum dibenarkan dengan ketentuan berikut ketentuan yang diatur dalam hukum internasional yang berlaku, yaitu Piagam PBB Pasal 39-51. Sedangkan peran PBB dalam intervensi kemanusiaan dalam konflik bersenjata dilakukan oleh Dewan Keamanan sebagai organ PBB di menjaga perdamaian dengan mengeluarkan keputusan dalam bentuk resolusi untuk daerah-daerah yang mengalami konflik. Oleh karena itu, yang diperlukan suatu perjanjian internasional yang mengatur dengan jelas tentang intervensi kemanusiaan, sehingga dalam pelaksanaannya, tetap konsisten dengan tujuan dan organ eksekutif intervensi kemanusiaan.

\section{Kata Kunci: Intervensi kemanusiaan, Dewan Keamanan PBB, Konflik Bersenjata}

\section{A. Pendahuluan}

Negara dalam hukum internasional dianggap sebagai subjek hukum utama. ${ }^{1}$ Dalam suatu hubungan antar subjek hukum internasional khususnya negara, sering terjadi pertentangan yang diakibatkan oleh perbedaan kepentingan. Dan tidak selamanya pertentangan tersebut dapat diselesaikan melalui penyelesaian damai. Pertentangan kepentingan inilah yang sering disebut dengan konflik. Konflik antar negara ini dapat disebabkan oleh beberapa faktor, seperti politik, ekonomi, ideologi, strategi militer, ataupun perpaduan antara kepentingan-kepentingan tersebut. ${ }^{2}$ Konflik dapat berupa konflik yang bersifat eksternal, yaitu yang terjadi antara negara dengan negara ataupun dapat berupa konflik yang bersifat internal yakni yang terjadi dalam suatu negara.

Penyelesaian konflik dapat digolongkan dalam dua kategori. Pertama, cara-cara penyelesaian damai, yaitu apabila para pihak dapat menyepakati untuk menemukan suatu solusi yang bersahabat. Kedua, cara-cara

\footnotetext{
${ }^{1}$ J.G. Starke, Pengantar Hukum Internasional I, (Jakarta: Penerbit Sinar Grafika, 1989), hlm. 12.

${ }^{2}$ Sri Setianingsih Suwardi, Penyelesaian Sengketa Internasional, (Jakarta: Penerbit Universitas Indonesia, 2006), hlm. 1.
} 
penyelesaian secara paksa atau dengan kekerasan, yaitu apabila solusi yang dipakai atau dikenakan adalah melalui kekerasan. ${ }^{3}$ Apabila negara-negara tidak dapat mencapai penyelesaian sengketa secara damai, satu-satunya pemecahan yang mungkin adalah melalui cara-cara kekerasan. Prinsipprinsip dari cara penyelesaian melalui kekerasan adalah perang dan tindakan bersenjata non perang, retorsi (retortion), tindakan-tindakan pembalasan (reprisals), blokade secara damai (pacific blockade), intervensi (intervention). ${ }^{4}$

Perang yang kemudian dikenal dengan istilah konflik bersenjata dalam perkembangannya bukan hanya antara negara dengan negara atau yang biasa dikenal dengan konflik bersenjata internasional, tetapi juga terjadi di dalam negara sendiri atau yang biasa dikenal dengan konflik noninternasional. ${ }^{5}$ Melihat dalam konflik bersenjata sering disertai dengan genosida, kejahatan terhadap kemanusiaan dan kejahatan perang maka Sekretaris Jenderal (Sekjen) PBB Koffi Anan pada tahun 1998 mendesak agar masyarakat internasional menyepakati untuk melakukan intervensi terhadap negara (yang berkonflik) untuk menghentikan pelanggaran-pelanggaran berat terhadap HAM. Kesepakatan tersebut dibuat atas dasar prinsip-prinsip yang sah dan universal serta dalam kerangka hukum internasional untuk melindungi orang-orang sipil dari pelanggaran besar-besaran HAM. ${ }^{6}$

Istilah intervensi mempunyai batasan sebagai suatu kegiatan yang dilakukan oleh suatu negara, kelompok dalam suatu negara, atau suatu organisasi internasional yang mencampuri secara paksa urusan dalam negeri negara lain.

Intervensi adalah campur tangan dari suatu negara terhadap masalah dalam negeri negara lain dengan tujuan untuk memelihara atau mengubah situasi yang ada. Salah satu bentuk intervensi dalam konflik bersenjata yang terjadi adalah konflik bersenjata yang terjadi di Rwanda dan Bosnia Herzegovina (bekas negara Yugoslavia). Sebagaimana diketahui di kedua negara tersebut telah terjadi konflik etnis. Pada awalnya konflik yang terjadi di kedua negara tersebut merupakan konflik bersenjata non internasional yang kemudian berubah menjadi konflik internasional karena adanya pihakpihak negara lain yang ikut serta dalam kedua konflik tersebut.

${ }^{3}$ J.G. Starke, Pengantar Hukum Internasional II, (Jakarta: Penerbit Sinar Grafika, 1989), hlm. 646.

${ }^{4}$ Ibid.

${ }^{5}$ Konflik bersenjata dibedakan menjadi dua, yaitu konflik bersenjata internasional dan konflik bersenjata noninternasional, Arlina permanasari dk, 1999, Pengantar Hukum Humaniter, Miamita Print ICRC, Jakarta, hlm. 129-139.

${ }^{6}$ Basic Facts About the United Nations, (New York: 1998), hlm. 72 sebagaimana dikutip dari Boer Mauna, Hukum Internasional Pengertian Peranan dan Fungsi dalam Era Dinamika Global, (Bandung: 2011), hlm. 647. 
Berdasarkan latar belakang tersebut di atas, untuk mengetahui dan memahami terhadap intervensi kemanusiaan yang berkembang saat ini, dikaji dan dianalisis secara mendalam agar dapat memberikan kejelasan pengaturan intervensi kemanusiaan dalam masyarakat internasional, untuk itu penulis ingin menyusun jurnal yang berjudul "Intervensi Kemanusiaan Menurut Hukum Internasional dan Implementasinya". Rumusan masalah dalam artikel ini yaitu:

1. bagaimana pengaturan intervensi kemanusiaan dalam hukum internasional ?

2. bagaimana peran PBB dalam melaksanakan intervensi kemanusiaan pada konflik bersenjata?

Metode Penelitian yang digunakan adalah metode penelitian hukum normatif dengan prosedur pengumpulan data yang sumber utamanya adalah bahan hukum yang berisi aturan-aturan yang bersifat hukum normatif. Data yang diperoleh dan diolah dalam penelitian hukum normatif adalah data sekunder yang berasal dari sumber kepustakaan. Studi kepustakaan dilakukan dengan cara mempelajari literatur, artikel, serta bahan bacaan lainnya yang berkaitan dengan penulisan artikel ini dilakukan melalui penelusuran kepustakaan ke perpustakaan Universitas Lampung, Perpustakaan Daerah Lampung, dan situs-situs internet yang berhubungan dengan penelitian ini.

\section{B. Pembahasan}

\section{Pengaturan Intervensi Kemanusiaan menurut Hukum Internasional}

Negara yang berdaulat dapat mengadakan hubungan dengan anggota masyarakat internasional lainnya, maupun mengatur segala sesuatu yang ada atau terjadi di luar wilayah negara itu tetapi sepanjang ada kaitannya dengan kepentingan negara itu. Hal ini di dasari oleh Piagam PBB Pasal 2 ayat (1) yang menerangkan bahwa hubungan antar negara berdasarkan persamaan derajat dan bebas.

Hubungan internasional menurut Pasal 2 ayat (4) bahwa negara dalam melakukan hubungan internasional tidak boleh menggunakan kekerasan terhadap integritas wilayah atau kemerdekaan politik negara lain. Kemudian Pasal 2 ayat (7) Piagam PBB menyatakan bahwa setiap negara dalam melakukan hubungan internasional dilarang untuk melakukan suatu intervensi kedalam urusan domestik negara lainnya, begitu pula dengan PBB dilarang untuk ikut campur dalam urusan domestik negara lain dan mewajibkan negara-negara yang berkonflik untuk menyelesaikan urusannya 
menurut ketentuan Piagam PBB. Hal ini berkaitan dengan adanya prinsip non intervensi sebagai salah satu pondasi dasar dalam hukum internasional. ${ }^{7}$

Prinsip non intervensi yang berkembang saat ini membuat kedaulatan negara saat ini tidak hanya dilihat sebagai hak negara, tetapi erat kaitannya dengan kewajiban negara untuk melakukan perlindungan hak asasi manusia. Karena tujuan dibentuknya sebuah negara adalah untuk melindungi setiap manusia baik warga negaranya maupun warga negara asing dari terjadinya pelanggaran hak asasinya. Hanya saja seringkali dalam penerapannya, negara yang bersangkutan menyalahgunakan hak dan kewenangan yang dimiliki, bahkan sampai mengenyampingkan nilai-nilai kemanusiaan, yang kemudian mengakibatkan kesengsaraan kepada rakyatnya. Oleh karena itu, dalam keadaan banyaknya pelanggaran berat HAM yang terjadi, pihak asing dapat masuk sebagai pihak ketiga untuk menyelesaikan permasalahan yang terjadi dan mengembalikan kondisi negara tersebut kepada keadaan semula, salah satunya dengan cara intervensi.

Humanitarian intervention atau Intervensi kemanusiaan secara umum adalah upaya untuk mencegah atau menghentikan pelanggaran hak asasi manusia (HAM) berat dengan kekuatan-kekuatan tertentu (diplomatik dan militer) di suatu negara, baik dengan atau tanpa persetujuan negara itu (negara mengalami konflik internal). Ketika terjadi suatu masalah kemanusiaan di suatu negara yang bersifat pelanggaran hak asasi manusia yang berat, maka masyarakat internasional dibenarkan untuk melakukan suatu tindakan intervensi.

Pelanggaran hak asasi manusia berat ada berbagai macam seperti kejahatan kemanusiaan, genosida dan kejahatan perang, dan lainnya. Pengenalan kejahatan terhadap kemanusiaan (crimes against humanity), pertama kali mulai dikenal dan telah menjadi hukum internasional positif yakni, setelah terjadi Perang Dunia II dalam Charter of International Military Tribunal Nuremberg (IMTN) tahun 1946, yang selanjutnya diatur dalam Charter of International Military Tribunal for The Far East (IMTFE) atau yang disebut juga dengan Piagam Tokyo pada tahun 1948, International Criminal Tribunal for Yugoslavia (ICTY) tahun 1993, International Criminal Tribunal for Rwanda (ICTR) tahun 1994, dan yang terakhir diatur dalam Statuta Mahkamah Pidana Internasional (Statute for an International Criminal Court) yang kemudian lebih dikenal sebagai Statuta Roma pada tahun 2002.

Pengaturan tentang intervensi kemanusiaan belum diatur secara tegas dalam hukum internasional. Akan tetapi, menurut Piagam PBB Pasal 24 tentang tugas dan fungsi Dewan Keamanan PBB, maka PBB melalui Dewan

\footnotetext{
${ }^{7}$ Lihat juga Aidan Hehir, Humanitarian Intervention After Kosovo, (England: Palgrave Mcmilan, 2008), hlm. 14.
} 
Keamanan berhak menjalankan kewajibannya terkait adanya ancaman terhadap keamanan internasional, atau pelanggaran perdamaian dan keamanan, dan agresi sesuai dengan tujuan-tujuan dan prinsip-prinsip PBB dan dengan sebisa mungkin mengurangi penggunaan kekuatan bersenjata, hal ini sesuai dengan Pasal 26 Piagam PBB. ${ }^{8}$

PBB juga dalam menyelesaikan suatu konflik di dasarkan pada Bab VI Pasal 33 Piagam PBB. PBB memiliki mandat untuk melakukan semua upaya agar konflik dapat diselesaikan secara damai melalui cara-cara negoisasi, mediasi, arbitrasi, penyelesaian hukum, serta cara damai lainnya. Selanjutnya Pasal 34 menyatakan bahwa PBB bisa melakukan investigasi setiap pertikaian (konflik) yang bisa membahayakan perdamaian internasional. Dewan Keamanan PBB dapat menyelidiki setiap pertikaian atau keadaan yang dapat menimbulkan ancaman terhadap perdamaian dan keamanan internasional.

Pada Pasal 36 Dewan keamanan dapat menganjurkan cara-cara penyelesaian yang dianggap sesuai dalam suatu pertikaian yang mengacu pada Pasal 33 atau suatu keadaan yang semacam itu. Selanjutnya Pasal 37 menerangkan bahwa apabila pihak-pihak yang tersangkut dalam pertikaian tersebut dianggap tidak dapat menyelesaikan masalahnya, maka Dewan Keamanan akan menetapkan apakah akan diambil tindakan menurut Pasal 36 ataukah mengambil cara-cara penyelesaian yang dianggap layak.

Anjuran tentang cara-cara penyelesaian yang dianggap layak seperti yang tercantum dalam Bab VII Piagam PBB, Pasal 39 menyebutkan bahwa Dewan Keamanan akan menentukan ada tidaknya suatu ancaman terhadap perdamaian dunia dan akan menganjurkan atau memutuskan tindakan apa yang harus diambil sesuai dengan Pasal 41 Piagam PBB yaitu bahwa Dewan Keamanan dapat memutuskan tindakan apa yang dapat dilakukan di luar penggunaan kekuatan bersenjata, seperti pemutusan hubungan ekonomi, alat-alat komunikasi, serta pemutusan hubungan diplomatik. Dan Pasal 42 yang menyatakan bahwa jika langkah-langkah politik dan ekonomi (berdasarkan Pasal 41) tidak bisa atau cukup mendorong pihak-pihak yang bertikai maka penggunaan kekuatan militer (kekuatan darat, laut, dan udara) dapat dibenarkan untuk menjamin kestabilan keamanan dan perdamaian internasional.Tindakan militer hanyalah langkah terakhir jika cara-cara lain tidak berhasil untuk melindungi penduduk dari pelanggaran HAM berat.

Intervensi kemanusiaan yang dilakukan oleh PBB tidak melanggar kebebasan politik sebuah negara. Tindakan tersebut hanya bertujuan untuk memulihkan hak asasi manusia pada suatu negara yang mengalami konflik. Setiap negara dan penduduknya tetap memiliki kebebasan politik. Atas

\footnotetext{
${ }^{8}$ Lihat juga Michael N. Barnett, The International Humanitarian Order, (New York: Routledge, 2010), hlm. 1.
} 
asumsi ini intervensi kemanusiaan tidak melanggar Piagam PBB. Intervensi atas dasar kemanusiaan yang dikenal sebagai humanitarian intervention ini dilakukan secara kolektif berdasarkan mandat Perserikatan Bangsa-Bangsa dan bertujuan untuk mengatasi masalah kemanusiaan. Hal ini sesuai dengan Pasal 50 Piagam PBB yang mengatur salah satu bentuk intervensi. Di mana intervensi ini dilakukan dengan tujuan untuk menyelesaikan persoalanpersoalan yang ada. Selanjutnya intervensi dalam rangka pembelaan diri terdapat dalam Pasal 51 Piagam PBB.

\section{Peran PBB dalam Melaksanakan Intervensi Kemanusiaan pada Konflik Bersenjata}

PBB merupakan organisasi yang paling besar selama ini dalam sejarah pertumbuhan kerja sama semua negara di dunia di dalam berbagai sektor kehidupan internasional. Menjaga perdamaian dan keamanan internasional erat kaitannya dengan prinsip kewajiban untuk melindungi (Responsibility to Protect $)^{9}$ merupakan tanggung jawab semua negara untuk melindungi rakyatnya sendiri, serta tanggung jawab masyarakat internasional untuk membantu negara-negara mewujudkan hal tersebut. Bila suatu negara gagal melindungi rakyatnya, maka sejumlah cara, baik itu politik, ekonomi, maupun diplomatik akan digunakan untuk membantu negara tersebut. Hal ini dilakukan dengan menggunakan banyak cara termasuk negoisasi, mediasi, dan penerapan sanksi. Intervensi militer hanya mungkin digunakan sebagai upaya terakhir untuk menghentikan kekejaman massal yang dilakukan secara multilateral dengan persetujuan Dewan Keamanan. ${ }^{10}$

Bab VI dan Bab VII Piagam PBB menjelaskan tentang penyelesaian pertikaian secara damai dan tindakan-tindakan yang diperlukan untuk menjaga perdamaian internasional, dapat dilakukan dengan upaya sebagai berikut :

a. Dewan Keamanan PBB dan Majelis Umum bisa menunjuk misi pencari fakta (fact-finding mission) untuk menyelidiki dan melaporkan dugaan pelanggaran hukum internasional. Dewan HAM PBB juga dapat mengirim misi pencari fakta serta menunjuk perwakilan khusus atau pelapor khusus untuk memberikan saran mengenai situasi tertentu;

b. misi-misi tersebut dapat sekaligus memberikan peringatan dini tentang krisis kemanusiaan yang terjadi dan bernegosiasi dengan para pemimpin

\footnotetext{
${ }^{9}$ Lihat juga ICISS, Responsibilty To Protect The Report, the International Development Research Centre, Canada, 2001, Page. 11-18.

${ }^{10}$ Rahayu, Eksistensi Prinsip Responsibility to Protect dalam Hukum Internasional, MMH, No.1, Jilid 41, Januari 2012 dapat diakses http://ejournal.undip.ac.id/ index.php/mmh/article/view/4212-9087-1-SM.pdf.
} 
negara di mana krisis tersebut berlangsung untuk mencari cara penyelesaian;

c. pemutusan hubungan ekonomi, komunikasi, serta hubungan diplomatik apabila dalam perundingan tersebut tidak ditemukan penyelesaiannya; dan

d. pertimbangan PBB untuk menggunakan kekuatan militer guna menghadapi kekerasan massal yang mendesak dan bersifat aktual. Hal penting yang harus diingat bahwa penggunaan kekuatan militer ini harus merupakan upaya terakhir bila suatu negara dipandang gagal melindungi warganya dan bila cara-cara damai yang ditempuh juga mengalami kegagalan.

Intervensi kemanusiaan sering disorot atas legitimasinya. Oleh karena itu, sebagian pakar hukum internasional berpendapat bahwa intervensi kemanusiaan tetap bisa dilakukan selama memenuhi persyaratan sebagai berikut: ${ }^{11}$

a. intervensi kemanusiaan harus di dasarkan atas alasan dan tujuan yang jelas, yaitu untuk melindungi hak asasi manusia;

b. harus dilakukan dengan memperhatikan syarat proporsionalitas, dan tidak eksesif; dan

c. harus di dasarkan aturan yang jelas untuk menghindari terjadinya eksploitasi oleh satu negara terhadap wilayah yang didudukinya.

Ketentuan yang terdapat dalam Bab VII Piagam PBB merupakan legitimasi dari intervensi kolektif terhadap suatu wilayah negara oleh PBB. Bahkan dengan tegas Sekjen PBB sebelumnya, Koffi Annan mengatakan bahwa: "Our job is to intervene: to prevent conflict where we can, to put a stop to it when it has broken out, or when neither of those things is possible

- at least to contain it and prevent it from spreading." ${ }^{12}$

Salah satu bentuk intervensi dalam konflik bersenjata yang terjadi adalah konflik bersenjata yang terjadi di Rwanda dan Bosnia Herzegovina (bekas negara Yugoslavia). Bosnia adalah pecahan dari negara federal Yugoslavia. Negara ini mempunyai catatan konflik berkepanjangan. ${ }^{13}$

Sejak Serbia dipimpin oleh Slobodan Milosevic terjadi kerusuhan etnis, kerusuhan etnis memuncak ketika disahkannya amandemen undangundang dasar Republik Serbia, yang menyatakan bahwa otonomi Kosovo berada di bawah pengawasan pemerintah Republik Serbia (Maret 1989). Dengan adanya keinginan etnis Albania untuk merdeka dan menjadikan Republik Kosovo sebagai negara yang berdaulat terpisah dari Serbia maka

${ }^{11}$ Idris, et.al., Penemuan Hukum Nasioanal dan Internasional, penerbit Fikahati Aneska, Bandung, 2012, hlm. 295 lihat dalam Imam Mulyana, Doktrin Intervensi dalam Piagam PBB dan Perkembangannya Dewasa Ini.

${ }^{12}$ Idris, et.al., Op.Cit., hlm. 286.

${ }^{13}$ Ibid. 
menimbulkan aksi agresif Slobodan Milosevic menumpas gerilyawan dan mengusir etnik Albania dari Kosovo, Milosevic menggelar KLA (Tentara Pembebasan Kosovo) untuk memberantas kelompok separatis yang mengupayakan kemerdekaan Kosovo. Sedangkan Serbia berpendapat Kosovo secara historis berada dalam kawasan dan sebagai bagian Serbia, dan bagi mereka UCK adalah kelompok teroris yang harus dihancurkan. Dengan adanya aksi brutal tersebut, mengakibatkan banyak korban berjatuhan dari warga sipil Albania. ${ }^{14}$

Di samping mengacu kepada sejumlah landasan moral, intervensi yang dilakukan oleh PBB dalam konflik Yugoslavia dibentuk berdasarkan resolusi PBB. Seperti salah satu bentuk dari resolusi tersebut ialah dibentuk Mahkamah Kejahatan Internasional, International Criminal Tribunal for Former Yugoslavia yang dibentuk berdasarkan Resolusi Dewan Keamanan PBB No. 827 pada tahun 1993 dan International Criminal Tribunal for Rwanda dibentuk berdasarkan Resolusi Dewan Keamanan No. 955 pada tahun 1994. PBB juga memberikan andil dengan mengeluarkan Resolusi Dewan Keamanan PBB 1244 pada 10 Juni 1999 menerangkan bahwa Kosovo ditempatkan di bawah administrasi PBB dengan tugas membentuk pemerintahan sementara untuk Kosovo, agar rakyat Kosovo mendapat otonomi luas dan pemerintahan sendiri. ${ }^{15}$

Pada kasus di Rwanda yang terjadi adalah konflik etnis yang antara suku Hutu dan Tutsi yang memakan korban jiwa dari pihak sipil. Sejak meletusnya perang antara pemerintah dengan pemberontak Front Patriotik Rwanda (FPR) di bulan Oktober 1990, telah dilakukan sejumlah upaya perdamaian dengan melibatkan sejumlah negara dikawasan itu. ${ }^{16}$

Kesepakatan damai tersebut menjelaskan bahwa PBB akan memainkan peranan besar melalui pasukan internasional yang netral (The Neutral National Forces-NIF). Pasukan ini bertugas mengawasi dan membantu implementasi perjanjian tersebut selama periode transisi yang akan berlangsung dalam kurun waktu 22 bulan. ${ }^{17}$

Berdasarkan rekomendasi dari misi tersebut, intervensi pasukan PBB akan dilakukan dalam empat tahapan. Tahap pertama, pengiriman tim yang terdiri dari 25 personil militer, 18 personil sipil, dan 3 polisi sipil setelah mendapat otorisasi formal dari Dewan Keamanan PBB. Misi ini akan berlangsung 90 hari dengan tugas mengamankan Kigali dan menciptakan kondisi yang diperlukan bagi pembentukan pemerintahan transisi. Tahap

\footnotetext{
${ }^{14}$ Peran PBB dalam Usaha Pencapaian Kemerdekaan Kososvo dapat diakses pada http://publikasi.umy.ac.id/files/journals/8/articles/1918/public/1918-2337-1-PB.pdf.

${ }^{15}$ Peran PBB dalam Usaha Pencapaian Kemerdekaan Kososvo, Loc.cit.

${ }^{16} \mathrm{http}$ //www.library.upnvj.ac.id/pdf/5FISIPS1IK/207613003/BAB\%20III.pdf diakses pada tanggal 16 januari 2014 pukul 23.46.

${ }^{17}$ Ibid.
} 
kedua, akan memakan waktu 90 hari dengan tugas utama demobilisasi dan integrasi angkatan bersenjata dan polisi nasional (Gendamerie). Pada tahap ketiga, memakan waktu sembilan bulan, integrasi angkatan bersenjata Rwanda akan dituntaskan dan kekuatannya dikurangi menjadi 1.240 personil. Pada tahap terakhir yang akan berlangsung selama empat bulan, misi PBB akan dikurangi menjadi berkekuatan 930 personil militer dengan tugas membantu mengamankan iklim yang diperlukan dalam tahapan akhir sampai dengan dilaksanakannya pemilu. ${ }^{18}$

Berdasarkan asas kemanusiaan bahwa manusia memiliki hak yang sama untuk hidup yang merupakan landasan moral untuk dilaksanakannya intervensi, PBB juga melaksanakan intervensi dalam konflik di Rwanda ini juga dapat dibenarkan dengan mengacu pada Bab VI, Bab VII, Pasal 55 dari Piagam PBB dan adanya sejumlah resolusi dan mandat Dewan Keamanan PBB. Selama kurun waktu antara Oktober 1993 sampai dengan Juli 1994, Dewan Keamanan PBB telah mengeluarkan sejumlah resolusi dan mandat terkait dengan konflik di negara tersebut. ${ }^{19}$ Berdasarkan Resolusi Nomor 812 PBB akan mendukung upaya untuk menjaga perdamaian dan keamanan di wilayah Rwanda khususnya untuk mencegah terjadinya konflik kembali. Kemudian PBB membentuk the United Nations Observer Mission UgandaRwanda (UNOMOR) melalui Resolusi Nomor 846 untuk memeriksa keadaan disana selama enam bulan. Setelah itu melalui Resolusi $872^{20}$ (1993), Dewan Keamanan PBB secara bulat membentuk UNAMIR, pasukan peace keeping berkekuatan 2.500 personil untuk memelihara perdamaian di Rwanda.

Pasukan penjaga perdamaian di Rwanda tersebut setidaknya dapat membantu memulihkan keadaan dan mengurangi jatuhnya korban jiwa kembali. Karena tujuan dari diadakannya intervensi kemanusiaan adalah meminimalisir kekerasan yang terjadi dan mencoba membuat proses perdamaian dan keamanan berlangsung. Apabila kekerasan terus berlangsung, maka jalan satu-satunya adalah meminimalisir korban yang jatuh dengan jalan menyelamatkan pihak yang lemah, biasanya dari kalangan penduduk sipil. Penyerangan terhadap penduduk sipil nonkombatan dapat menyeret pelakunya ke Mahkamah Internasional kejahatan perang untuk diadili.

\footnotetext{
${ }^{18}$ Ibid.

${ }^{19}$ Ibid.

${ }^{20} \mathrm{~S} / \mathrm{RES} / 872$ "Decides to establish a peace-keeping operation under the name "United Nations Assistance Mission for Rwanda" (UNAMIR) for a period of six months subject to the proviso that it will be extended beyond the initial ninety days only upon a review by the Council based on a report from the Secretary-General as to whether or not substantive progress has been made towards the implementation of the Arusha Peace Agreement".
} 


\section{Penutup \\ 1. Kesimpulan}

Berdasarkan pembahasan dan penguraian fakta yang telah dilakukan sebelumnya, dapat ditarik kesimpulan sebagai berikut :

a. instrumen hukum internasional menyebutkan secara eksplisit bahwa prinsip nonintervensi merupakan salah satu prinsip fundamental dalam hukum internasional. Hal tersebut dapat dilihat dalam Pasal 1 (1), 2 (4), (7) Piagam PBB. Akan tetapi, Intervensi kemanusiaan tidak melanggar kebebasan politik sebuah negara. Tindakan tersebut hanya bertujuan untuk memulihkan hak asasi manusia pada suatu negara. Setiap negara dan penduduknya tetap memiliki kebebasan politik. Pengaturan intervensi kemanusiaan terdapat dalam Piagam PBB yang diatur dalam Pasal 2 ayat (4), Pasal 24, Pasal 25, Pasal 26, Pasal 33, Pasal 34, Pasal 39, Pasal 40, Pasal 49, Pasal 50, dan Pasal 51 . Selain itu, intervensi juga mendapatkan legitimasinya berdasarkan prinsip-prinsip umum seperti prinsip kemanusiaan dan prinsip hukum HAM yaitu prinsip kesetaraan; dan

b. intervensi kemanusiaan dapat dilakukan oleh PBB melalui Dewan Keamanan. Dewan Keamanan melakukan intervensi kemanusiaan melalui tahap pencarian fakta-fakta, diplomasi, dan penggunaan militer. Dewan Keamanan menunjuk misi pencari fakta untuk menyelidiki dan melaporkan dugaan pelanggaran hukum internasional, misi-misi tersebut dapat sekaligus memberikan peringatan dini tentang krisis kemanusiaan yang terjadi dan bernegosiasi dengan para pemimpin negara di mana krisis tersebut berlangsung untuk mencari cara penyelesaian, dan upaya penggunaan kekuatan militer guna menghadapi kekerasan massal yang mendesak dan bersifat aktual. Penggunaan kekuatan militer ini harus merupakan upaya terakhir bila suatu negara dipandang gagal melindungi warganya dan bila cara-cara damai yang ditempuh juga mengalami kegagalan.

\section{Saran}

Berdasarkan kesimpulan yang didapat maka dapat diajukan beberapa saran sebagai berikut:

a. instrumen hukum internasional tidak menyebutkan secara eksplisit tentang pengaturan intervensi kemanusiaan. Oleh karena itu, diperlukannya pembentukan suatu pengaturan mengenai tindakan intervensi kemanusiaan yang dapat dilakukan oleh organisasi internasional. Suatu bentuk perjanjian internasional yang mengatur dengan jelas tentang intervensi kemanusiaan sehingga dalam pelaksanaannya tetap sesuai dengan tujuannya yaitu untuk menjaga perdamaian dan keamanan internasional. 
b. Pembentukan pengaturan tersebut disertai dengan pembentukan organisasi internasional yang memiliki wewenang secara penuh melakukan intervensi kemanusiaan sehingga tujuan utama dari dilakukannya intervensi dapat dipenuhi tanpa ada campur tangan dari pihak lain yang memiliki kepentingan berbeda dari tujuan dilakukannya intervensi.

\section{Daftar Pustaka}

\section{A. Buku}

Barnett, Michael, 2010. The International Humanitarian Order, New York: Routledge.

Hehir, Aidan, 2008. Humanitarian Intervention After Kosovo, England: Palgrave Mcmilan.

ICISS, 2001. Responsibilty To Protect The Report, Canada: the International Development Research Centre.

Idris (ed), 2012. Penemuan Hukum Nasional dan Internasional, Bandung: Fikahati Aneska.

Mauna, Boer, 2011. Hukum Internasional Pengertian Peranan dan Fungsi dalam Era Dinamika Global, Bandung.

Permanasari, Arlina, dkk, 2000. Pengantar Hukum Humaniter, Jakarta: Miamita Print ICRC.

Starke, J,G., 1989. Pengantar Hukum Internasional I, Jakarta: Penerbit Sinar Grafika.

----------, 1989. Pengantar Hukum Internasional II, Jakarta: Penerbit Sinar Grafika.

Suwardi, Sri Setianingsih, 2006. Pengantar Hukum Organisasi Internasional, Jakarta: UI Press.

\section{B. Jurnal, Artikel, Makalah, dan Sumber Internet lainnya}

http://www.library.upnvj.ac.id/pdf/5FISIPS1IK/207613003/BAB\%20III.pdf. http://www.un.org/en/sc/documents/resolutions/1994.shtml.

https://www.google.com/\#q=resolusi $+\mathrm{dk}+\mathrm{pbb}+$ no+743+tahun $+19 \quad 92$.

Peran PBB dalam Usaha Pencapaian Kemerdekaan Kososvo dapat diakses pada

http://publikasi.umy.ac.id/files/journals/8/articles/1918/public/19182337-1-PB.pdf.

Rahayu, Eksistensi Prinsip Responsibility to Protect dalam Hukum Internasional, $M M H$, No.1, Jilid 41, Januari 2012 dapat diakses 
http://ejournal.undip.ac.id/index.php/mmh/article/view/4212-9087-1SM.pdf.

Al Syahrin, M. N. (2018). Kebijakan Poros Maritim Jokowi dan Sinergitas Strategi Ekonomi dan Keamanan Laut Indonesia. Indonesian Perspective, 3(1), 1-17.

Al Syahrin, M. N. (2018). Logika Dilema Keamanan Asia Timur dan Rasionalitas Pengembangan Senjata Nuklir Korea Utara. Intermestic: Journal of International Studies, 2(2), 116-138.

Al Syahrin, M. N. (2018). Kompleksitas Keamanan Kawasan dan Tantangan Kerja Sama Keamanan Asia Timur. Nation State Journal of International Studies, 1(1), 24-44.

Al Syahrin, M. N. (2018). Donald Trump dan Reorientasi Kebijakan Keamanan Amerika Serikat Terhadap Program Pengembangan Senjata Nuklir Korea Utara. Jurnal Ilmiah Hubungan Internasional, 14(1), 97-111.

Al Syahrin, M. N. (2018). China versus Amerika Serikat: Interpretasi Rivalitas Keamanan Negara Adidaya di Kawasan Asia Pasifik. Global Strategis, 12(1), 145-163.

Al Syahrin, M. N. KEAMANAN ASIA TIMUR.

Insani, P. A., \& Azwari, T. Al Syahrin, M. N. BUREAUCRATIC TRANSFORMATION AS A SUPPORT OF SMART CITY.

Al Syahrin, M. N., Sompa, A. T., Budhi, S., Rachman, D., \& Alunaza, H. (2020). Bottom-Up Model Analysis of Community Involvement in the Sister City Cooperation for Flood Mitigation in East Kalimantan. Revista UNISCI, (53).

Rachman, D., \& Al Syahrin, M. N. (2018). Pelatihan Komunikasi Teman Sebaya Sebagai Upaya Meminimalisasi Bullying di Sekolah Menengah Atas Negeri (SMA) 16 Samarinda. Jurnal Abdimas Mahakam, 2(2), 48-56. 
Dwiyanti, A. A. R., \& Al Syahrin, M. N. (2018). Penerapan Developmental State Dalam Sektor Industri Kecil Menengah Di Indonesia: Studi Kasus Kabupaten Bone. Journal of Islamic World and Politics, 2(1), 205-227.

Al Syahrin, M. . GM Rukmana, D Rachman, A Harakan, T Farida. Sister City Bottom Up Collaborative Model Plan As a Major Flooding Mitigation in Samarinda Environmental Science, Society, and Technology, WESTECH 2018, 1-12.

\section{Dokumen}

United Nations Charter (Piagam PBB).

United Nations Security Council Resolution S/RES/827 (1993), on the establishment of an international tribunal for the Former Yugoslavia, (tentang pembentukan Pengadilan Internasional untuk penjahat negara bekas Yugoslavia).

United Nations Security Council Resolution S/RES/812 (1993), the contribution of United Nations might assist the process towards political settlement in Rwanda, (upaya PBB untuk menjaga perdamaian di Rwanda).

United Nations Security Council Resolution S/RES/846 (1993), on the establishment of the United Nations Observer Mission UgandaRwanda (UNOMOR) (tentang pembentukan UNOMOR).

United Nations Security Council Resolution S/RES/872 (1993), on the establishment of the UN Assistance Mission for Rwanda (tentang pembentukan UNAMIR).

United Nations Security Council Resolution S/RES/955 (1994), on the establishment of an international tribunal for Rwanda and the adoption of the statute of the tribunal (tentang pembentukan International Criminal Tribunal for Rwanda).

United Nations Security Council Resolution S/RES/1244 (1999) on the situation relating Kosovo (tentang pemerintahan kosovo dibawah naungan PBB). 